\title{
Reinventing Gabions: How Collaboration Led to New Methods of Building Laterally Stable Walls
}

RICK SOMMERFELD

University of Colorado Denver

In the memoirs of well-known engineers (consider Informal and Crossover by Cecil Balmond or An Engineer Images by Peter Rice) anecdotal tales of early design conversations dominate the writings. It is in this dialogue where common goals are struck, concepts are realized, and the foundations of the projects emerge.

The question then is not if we collaborate with engineers, but how and when we collaborate with them.

For ColoradoBuildingWorkshop, the design-build program at the University of Colorado Denver, the structural engineer is present at the first client meeting and remains engaged throughout the design process. This early engagement with students is critical to successful project outcomes. To stress the importance of these conversations, and better integrate structural engineering into the curriculum, the department now offers a support course to compliment the design-build studio co-taught by Andy Paddock, PE. This early and consistent collaboration has yielded a series of innovative projects perhaps none more successful than the 2018 project in Rocky Mountain National Park.

The project brief called for four privies along the historic Long's Peak Trailhead. Located at elevations between 10,500 $-12,800$ feet above sea level, and as far as five miles from the trailhead, each of the three sites are inaccessible by vehicle. Given the sensitive flora and historical nature of the trail, each privy was required by the National Park Service (NPS) to blend into the surroundings while minimizing the physical impact to the landscape. Additionally, each structure needed to be erected in less than eight days to decrease the exposure each student would face building at such an extreme elevation. To add to the complexity, the NPS asked that each structure be light enough to be lifted by a helicopter but strong enough to sustain winds of more than 225 miles per hour.

The final design solution is a series of prefabricated structural gabion walls. Each of the steel louvers between gabion modules act as a moment frame connected by a continuous ring plate above the walls. The ring plate transfers lateral loads from one leg of the moment frame to a corresponding leg on the opposite wall. This ring plate is key to the structural system, effectively bending and transferring lateral forces around the structure, allowing the moment frames to work along their lines of action. To keep the structure as light as possible the gabion rocks were collected on-site. The rocks

\author{
ANDY PADDOCK \\ RMG Engineers
}

act as ballast for the structure and laterally brace each of the $1 / 8$ " thick steel plate moment frames to prevent them from laterally buckling. This hybrid structural system allowed the steel plate louvers to be reduced from $1 / 4$ " to $1 / 8$ " plate and the gabion walls to be reduced from their original 18" thickness down to 12 inches. This minimized onsite construction, cut structure weight by nearly $40 \%$, and reduced onsite rock collection, and therefore the impact to the flora, by $33 \%$. 
REINVENTING THE GABION:

ColoradoBuilding Workshop, UNIVERSITY OF COLORADO DENVER
Authors: Erik "Fick" Sommerfeld, Assistant Professor Ere "
William Koning, Bixler Designt-Build Fellovt

In the memoirs of well-known engineers (consider Informal and Crossover by Cecil Balmond
or An Engineer Images by Peter Rice) anecdotal tales of early design conversations dominate the writings. It is in this dialogue where common goals are struck, concepts are realized, an

The question then is not if we collaborate with engineers, but how and when we collaboralo For ColoradoBuildingWorkshop, the design-build program at the University of Colorado Denver, the structural engineer is present at the first client meeting and remains engaged project outcomes. To stress the importance of these conversations, and better integrate structural engineering into the curriculum, the department now offers a support course compliment the design-build studio co-taught by the engineer. This early and consistent the 2018 project in Rocky Mountain National Park.
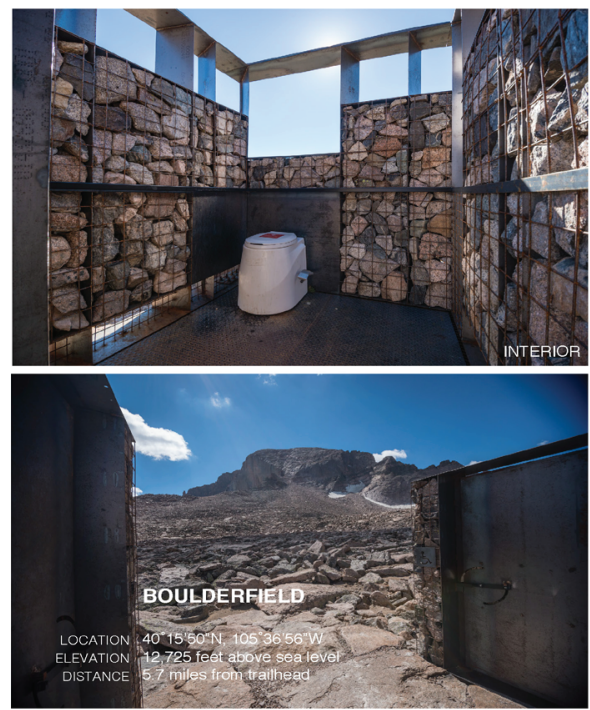

The project brief called for four privies along the historic Long's Peak Trailhead. Located at

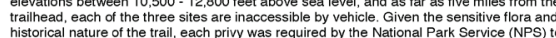
(I) s. each structurt would face building at such an extreme elevation To add to the complexity. the NPS asked that each structure be light enough to be
sustain winds of more than 225 miles per hour

The final design solution is a series of prefabricated structural gabion walls. Each of the steel buvers between gabion modules act as a moment frame connected by a continuous ring to a corresponding leg on the opposite wall. This ring plate is key to the structural system. effectively bending and transterring lateral forces around the structure, allowing the moment irames lowo loon herite each of the $1 / 8^{n}$ thick steel plate moment frames to prevent them from laterally buckling. This hybrid structural system allowed the steel plate louvers to be reduced from $1 / 4$ to $1 / 8$ " plate minimized onsite construction, cut structure weight by nearly $40 \%$, and reduced onsite rock

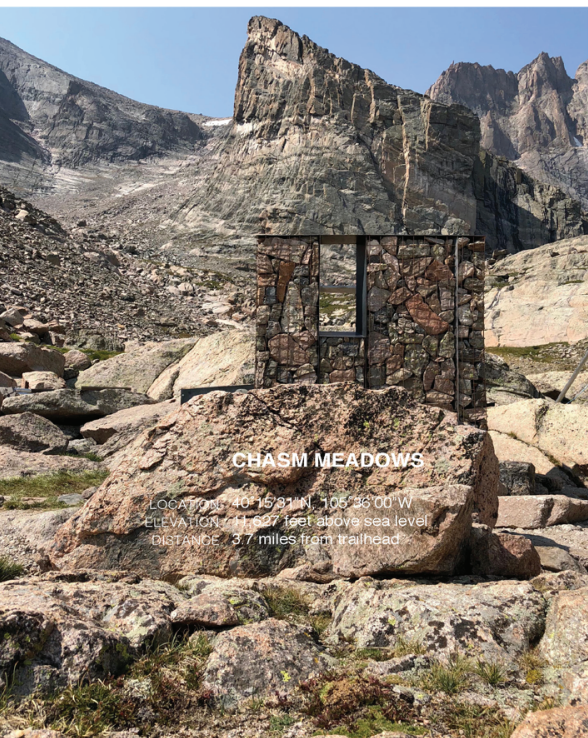

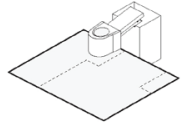

ACCESSIBLE BATHROOM STANDARDS The National Park Service's ABA guidelines
set the footprint of the structure.

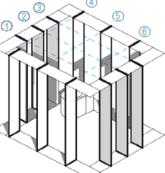

MOMENT FRAME STRUCTURE Based loosely on Toyo Ito and Cecil
Balmond's structural solution to the Serpentine Pavilion in 2002 the ROMO
Privies used $1 / 8$ " steel plate louvers a moment frames.

TRIANGULATING LATERAL LOADS Each moment frame is adjusted to take triangulated to brace the structure again

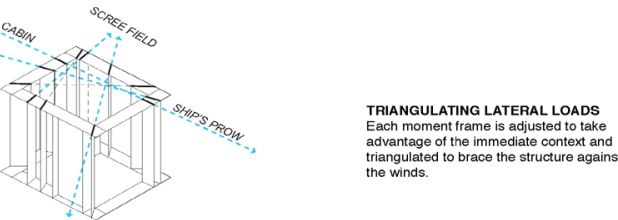

Bag Enclosure

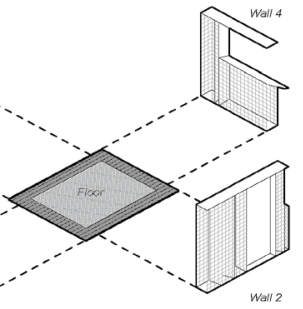

PREFABRICATION

the gabion cages. Prefabricated off-site by down into walls and floors, and shioken the site using a KMax Helicopter.

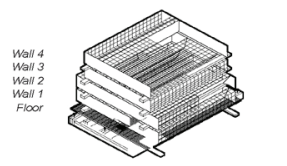

$\longrightarrow$

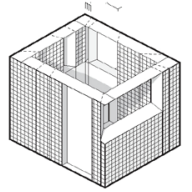

Each structure was light enough to be
delivered to the remote locations using jus
two loads The first was a stack of walls two loads. The first was a stack of walls
supported by the floor. The second was the

ON-SITE CONSTRUCTION
Once reassembled on the mountain the cages are filled with rocks collected from the
site. The gabions are loaded from the that flip open. Once filled they are secured

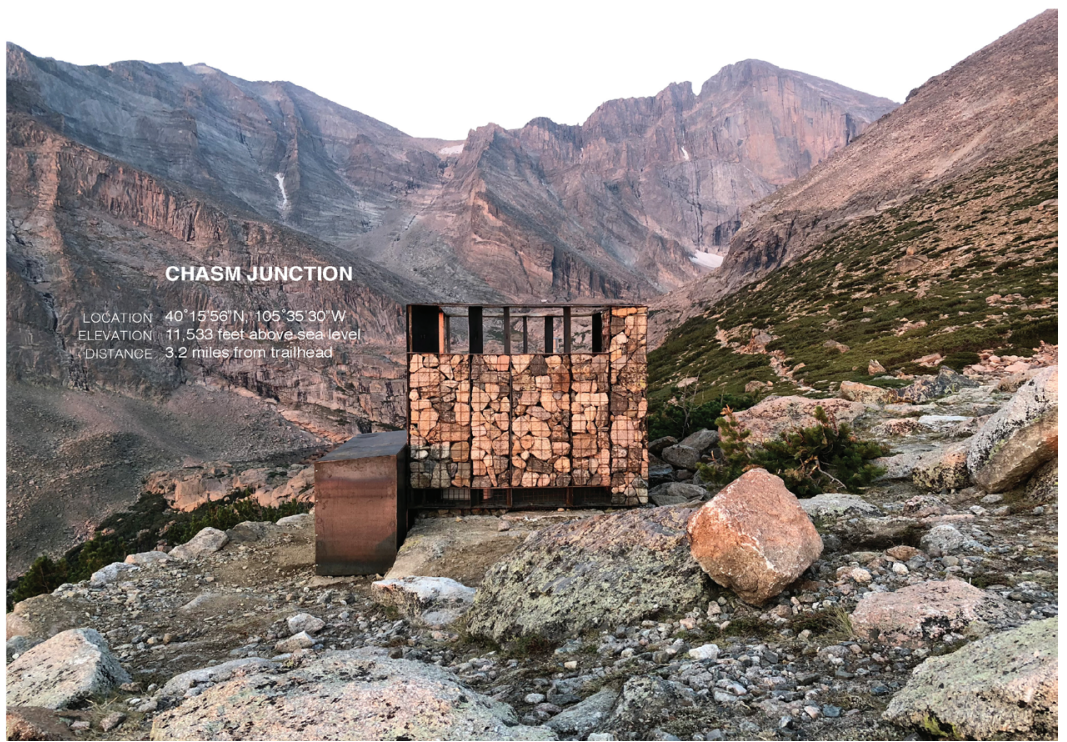

